Fecha de recepción: octubre 2019

Fecha de aceptación: diciembre 2019

Versión final: noviembre 2021

\section{Hipermoda, la moda \\ rizoma}

María Valeria Tuozzo *

Resumen: Este escrito trata de mostrar cómo siendo la moda afín a su propia lógica, se renueva y resurge de las cenizas como el Ave Fénix; lejos de perecer, se resignifica. Modificando los campos de producción y consumo, alterando los sentidos manifiestos en el imaginario social, en los sujetos; adaptándose al nuevo paradigma rizomático en el cual el individualismo y la globalización, la humanidad interconectada, las prótesis tecnológicas son causa y consecuencia de estas nuevas cosmovisiones del mundo. La moda no queda exenta de ello y se manifiesta, también, en rizoma.

Palabras clave: Moda - hipermoda - sociedad - rizoma - nuevas subjetividades - cultura - paradigmas.

[Resúmenes en inglés y portugués en la página 50]

$\left.{ }^{*}\right)$ Licenciada en Sociología, Universidad de Buenos Aires. Licenciatura en Filosofía Universidad de Buenos Aires. Posgrado en Gestión Cultural y Comunicación (FLACSO). Posgrado en Escrituras y Creatividad (FLACSO). Profesora de la Universidad de Palermo en el Área de Investigación y Producción de la Facultad de Diseño y Comunicación.

\title{
Introducción
}

Nos proponemos analizar las características que la moda ha tomado a partir de la observación de sus propias manifestaciones en la actualidad y así ofrecer posibles líneas de reflexión acerca de los paradigmas que nos atraviesan, partiendo del aporte de conceptos que consideramos relevantes desde la Sociología y la Filosofía.

La moda es un complejo sistema de producción de indumentaria que surge propiamente en la época Moderna bajo circunstancias que permiten su desarrollo y auge, entre ellos la Revolución Industrial y la Revolución Francesa; impone cierta lógica de valores; establece ritmos de alternancia de las prendas y como todo sistema que surge del quehacer humano, comunica: impone sentidos, establece normas y produce identidades.

En su origen mítico es hija del Capitalismo y hermana de la Muerte; tiene en sus ancestros las características propias del devenir del Ave Fénix. Resurge de sus propias cenizas 
una y otra vez bajo distintas formas. Es esa su propia lógica de funcionamiento y adopta diferentes manifestaciones acordes a lo que los paradigmas imponen. La moda slow o fast fashion, sustentabilidad, textiles inteligentes, el exacerbado individualismo, las identidades de género, el cosplay, entre otros, como consecuencia de la fascinación por la imagen son muestras de su existencia bajo la posmodernidad. Esto quiere decir que la moda no ha muerto, sino que muta, se recicla, y resurge; con otras características, pero siendo ella misma.

Este sistema de producción y comunicación, de medición de tiempos culturales y de accionar performativo sobre las identidades se muestra como otra institución más. Thomas Carlyle (1976) en Sartor Resartus propone las instituciones como "vistientes del sujeto" (p. 46); si la moda se incluye entre ellas y está en crisis en su paradigma disciplinador como moda universal y disciplinaria; el modelo reversionado de la institución moda en el postcapitalismo se impone con otras características, las de la sociedad de control (Deleuze, 1991) libre, seductora, inclusiva de las más diversas estéticas por reconocer en cada una o en cada uno potenciales consumidores y al mismo tiempo mercancías de sí mismos, como expresa Sibilia (2010) "los modos de ser constituyen mercaderías muy especiales, que son adquiridas y de inmediato descartadas por los diversos tipos de consumidores a los cuales se dirigen, alimentando una espiral de consumo en aceleración constante" (p. 12). Por otra parte, "Así, la ilusión de una identidad fija y estable, tan relevante en la sociedad moderna e industrial, va cediendo terreno a los kits de perfiles estandarizados o identidades Prêtà-porter" (Sibilia, 2010, p. 28). Cada kit de perfil pasa a ser un juego en el sistema y en la producción de identidades. Teniendo en cuenta que el vestir es una práctica corporal contextuada (Entwistle, 2002) habrá que saber leer e interpretar estas pequeñas performances cotidianas que ya no coinciden con una lógica universal y necesaria. De esta manera se da lugar a los nuevos perfiles descartables e intercambiables en distintos sentidos. El crossplay, por ejemplo. No hay autoridad ni pensamiento lineal; hay rupturas, fragmentaciones, puntos de fuga y grietas por donde se dejan ver otras subjetividades, otros mensajes, otras identidades. Una forma más de hacer converger la virtualidad y la realidad. Los superhéroes ya no son personajes lejanos de comics, series y filmes; son los sujetos reales jugando a ser otros. Lo lúdico aparece en la escena postmoderna y como tal y para cada caso presenta sus propias reglas de juego, que pueden ser familiares, pero no exactamente iguales; y cada performance establece un universo propio y por lo tanto múltiples universos.

\section{Moda Rizoma}

Los nuevos conceptos no son dualistas, no es moda o no moda. En medio y por fuera de ellos podemos encontrar las más diversas expresiones. "En una perspectiva perfectamente coherente con el paradigma digital, la información es la esencia de todos y cualquier entidad" (Sibilia, 2010, p. 46). El pensamiento se vuelve en representación arabesca, con curvas y puntos que no implican jerarquías. Recordemos lo que es Rizoma para Deleuze y Guattari (1991) el rizoma se compone a través de los "principios de conexión y heterogeneidad: cualquier punto del rizoma puede ser conectado con cualquier otro, y debe serlo" 
(p. 13). Sosteniendo que la moda no ha muerto podemos señalarla como Hipermoda para poder explicar sus más diversas expresiones y acorde a este mundo tecnológicamente globalizado. La moda se manifiesta en rizoma; la Moda Rizoma: a la vanguardia se le suma lo vintage, lo retro y lo tecnológico digital; ejemplos en el mundo del vestir abundan y se renuevan y multiplican a velocidades digitales. Para el momento que el lector se encuentre con estas reflexiones el ejemplo que sigue es antiguo, pero vale su señalamiento y el ejercicio de continuar la búsqueda. Víctor and Rolf, los diseñadores holandeses, realizan un desfile de alta costura otoño 2015 en el que cada modelo viste un cuadro deconstruido para volver a ser colgado en la pared-museo, pasarela, una vez vuelto a armar por los mismos diseñadores que centralizan la escena, la pregunta, entre otras, que surge es: la moda una manifestación más del arte.

La noción de Rizoma proviene del nombre de la estructura de algunas plantas; en ellas los brotes pueden ramificarse en cualquier punto, así como engrosarse transformándose en un bulbo o tubérculo; el rizoma de la botánica, que puede funcionar como raíz, tallo o rama sin importar su posición en la figura de la planta, sirve para ejemplificar un sistema cognoscitivo, aquí animándonos a la metáfora para sugerir un nuevo Sistema de la Moda.

\section{Del concepto a la producción y el consumo}

La moda rizoma dibuja en sus manifestaciones este esquema, se recicla y recicla. En rizoma es como se dibuja el mapa de la producción global de la moda como en el modelo fast fashion, los centros de producción concreta de la mercancía son distintos a los centros desde donde la empresa comercializa la fantasía al consumidor, incluso la proveeduría de la materia prima para la confección del producto proviene de otros lugares, con todo el dibujo de la producción, comercio y consumo queda signado por una cartografía que territorializa y desterritorializa mercancías y consumidores. En un ritmo de aceleración constante el mercado se ocupa de satisfacer la demanda permanente y continua de los consumidores.

Los nombres instituidos en el campo de la producción deben alternar con los anónimos perfiles para permanecer en el campo. Son la griffe versus estilistas, diseñadores, influencers, bloggers. Así la legitimidad de aquellos fundadores del glamour y misterio del diseñador la griffe se ve en competencia con ignotos prosumidores-estilistas, asesores de imagen, y demás protagonistas que en mayor o menor exposición colaboran con el sistema. A la opacidad del campo de producción en el que la ortodoxia hacía difícil el ascenso de quienes como nuevos diseñadores buscaban dicha legalidad, se le opone la transparencia y legitimidad de la heterodoxa comunicación y producción de la vestimenta en épocas posmodernas. La autoridad del nombre ha sido reemplazada en ese formato de corrientes de información que impone la navegación por infinitas legalidades donde cada cual se convierte en productor y consumidor de los propios contenidos, del propio estilo, del propio relato; de ser quien se desea ser cada día según estados de ánimos, contextos; la fijación de una personalidad se evade en el juego de la presentación social. La categoría es prosumidor porque, como bien lo demuestran los influencers, it girls, bloggers, youtu- 
bers son los que no sólo consumen los productos, sino que además producen sus propios contenidos, sus propias estéticas, su propio marketing. De esta manera "las redes globales de telecomunicación y sus diversos aparatos de conexión ofrecen acceso a las novedosas experiencias virtuales, dispensando la organicidad del cuerpo, la materialidad del espacio y la linealidad del tiempo" (Sibilia, 2010, p. 52). Los campos de producción y de consumo pierden sus límites, se desterritorializan y se reterritorializan en cuerpos, en espacio y en tiempos que se redefinen en este período de la Moda Rizoma.

\section{Del diseño del imaginario y del vestir}

Señala Gianni Vattimo (1989) que "la sociedad posmoderna se estructura a partir de la massmediatización de la realidad y que lo que en verdad ha muerto es esa única verdad que plantea la modernidad" (p. 87). Con su deceso aparece "la estetización de la existencia, el establecimiento de una cultura del consumo generalizado, el fin de los colonialismos hegemónicos y la irrupción de minorías" (p. 87). Es sobre todo primordial a la moda la cuestión de la estetización de la existencia, todo o casi todo pasa por la imagen; el discurso de la moda interpela a cada sujeto; no ya con una única verdad, sino con una adecuación para cada uno. Encaja a la perfección creando y generando ilusiones constantes sobre las apariencias; la imagen repetida al infinito en las redes sociales es Narciso reflejándose en las pantallas. No menor importancia cobra la irrupción de las minorías, porque como un movimiento de equilibrio de la tendencia global, la localidad y las minorías son componentes insoslayables en movimientos o corrientes alternativas que con pretensiones revolucionarias cuestionan el des-orden establecido.

Para Cornelius Castoriadis (2013) el ser humano es actividad que crea, es un hacer que inventa, es un hacer que genera el mundo que habita y al hacerlo se inventa así mismo. El ser humano imagina, despliega, genera algo allí donde no había, y en este acto se transforma a sí mismo. Esas creaciones de la industria cultural, producto del imaginario individual con otros articulándose con lo social transforma asimismo la realidad y el sujeto; a partir de allí nuevas significaciones se ponen en juego. Desde este punto de vista, el nivel de existencia del ser humano empieza por lo imaginario. El cambio social implica discontinuidades. Todas las sociedades construyen sus propios imaginarios: instituciones, leyes, tradiciones, creencias y comportamientos, sus propias modas. A medida que se desarrolla el proceso histórico social hay grandes significaciones que comienzan a perder sentido. Las significaciones sociales se modifican de acuerdo con las necesidades de un momento histórico, social, político y económico determinado. Aparecen nuevas significaciones que provienen del fondo del ser histórico social, del imaginario social radical. La moda como expresión del imaginario social efectivo ve afectado su contenido a partir de la globalización y el avance infinito de la tecnología digital. El ser humano modifica y crea su entorno para cubrir las necesidades tanto individuales como sociales y en el proceso estas modificaciones están íntimamente ligadas a una época y cultura determinadas. De esta manera se comprende como a partir de la tecnología digital un nuevo mundo ha sido modificado, en palabras de Hervé Fischer (2011): 
La tecnociencia contemporánea tiene en cuenta la diversidad del tiempo, las discontinuidades, las lógicas de las catástrofes, el caos, el principio de incertidumbre de Heisenberg y las complejidades, lógicas imprecisas y lógicas de participación más cercanas a las afinidades alquímicas que la lógica de la identidad clásica” (p. 107).

Un nuevo imaginario en consolidación se va forjando en base a y por el proceso de digitalización. Por ejemplo: "Forma parte de esa vertiente los diversos prototipos de computadoras para usar o wearables, la tecnología transparente que se adhiere a las ropas o a los cuerpos de los usuarios de forma cada vez más integrada y disimulada” (Sibilia, 2010, p. 52). Los wearables como los Smartphone construyen una nueva subjetividad en la cual los aspectos psicológicos, fisiológicos e intelectuales de los sujetos-usuarios-dividuos-prosumidores son modificados.

El surgimiento exponencial de aplicaciones en los celulares se relaciona con el desarrollo de los comportamientos sociales, con la capacidad de archivar historias o no; allí reside la diferencia entre Instagram y Snapchat, por ejemplo. Aplicaciones destinadas a mostrar-se están a la orden del día, para hacer una vidriera de la vida privada y una publicidad de la subjetividad virtual; el anonimato ya no es moneda corriente. "En la sociedad expuesta, cada sujeto es su propio objeto de publicidad" (Byung-Chul, 2013, p. 12) y como toda publicidad tiende a destacar los rasgos positivos de la mercancía (cuerpo-mercancía): "El veredicto general de la sociedad positiva se llama $<$ me gusta $>$. Es significativo que Facebook se negara consecuentemente a introducir un botón de $<$ no me gusta $>$. La sociedad positiva evita toda modalidad de juego de la negatividad" (Byung-Chul, 2013, p. 10), evita el envejecimiento, Photoshop; evita el estrés, App para controlar crisis de ansiedad; evita el aburrimiento, Candy Crush; evita la falta, todo en la subjetividad debe ser total; y aun así aparece la falta dado que nunca nada es suficiente; siempre se desea consumir algo más. La obsolescencia programada está dispuesta a ese fin, a cubrir en un lapso breve de tiempo un deseo convertido en necesidad y a responder a esa necesidad en un breve lapso.

\section{De la historia}

La moda ha sido disciplinaria en las sociedades de las que habla Foucault (1995) citado en Deleuze en Poscriptum (1991); porque ha sabido dictar en su forma más autoritaria las pautas que cada sujeto debía cumplir. La Hipermoda es controladora, sutil, seductora porque permite fantasear con las infinitas posibilidades de ser otro, de extender la vida más allá de las dimensiones conocidas. La Hipermoda, gracias a la tecnología medicinal, ha encontrado la piedra filosofal, esa que anhelaron encontrar con la alquimia nuestros antepasados, fuente de juventud eterna; las personas máscaras se moldean a su gusto a través de cirugías plásticas de todo tipo. La Hipermoda con su lógica rizomática, con su transitar huidizo y fugaz, desubica a los sujetos, genera perplejidad y vacilación. La proliferación de programas sobre moda, sobre estilismo, programas que transforman a los sujetos, son formas de servicios que presta la moda. Son los tiempos del servicio. En la Hipermoda es 
conveniente hablar de diseño, es su reconversión, su reformulación en tiempos globales, líquidos. Explotan, derraman los diseños; hasta la vida es diseñada por la genética y la medicina. La indumentaria se mixtura; se vulgariza, kitsch. Imitación, parodia, pastiche de la moda. La Hipermoda es, en la actualidad, el pastiche; la fusión de estilos. Si históricamente es posible reconocer estéticas bien diferenciadas a lo largo de los siglos y las décadas del SXX, en el presente esto no es tan evidente. La última gala del Met invitó al Camp, celebrada en mayo 2019, las más diversas poses, insólitas e insospechadas se dieron paso en la alfombra más kitsch de la historia.

Haciendo un poco de historia la moda hubo de esperar para su nacimiento a la Edad Media, y más precisamente al Renacimiento. Esperó por los primeros burgueses, intrépidos comerciantes con ansias de ascender en la escala social hasta donde se ubicaban reyes y nobles. De allí en más, su crecimiento ha sido inexorable. Siguiendo a Margarita Riviere (1994) en su texto ¿Comunicación o Incomunicación? las etapas de constitución y afianzamiento de la Moda como sistema se suceden en tres momentos. Un primer momento que es el de la moda aristocrática; los reyes y la nobleza en general son quienes tienen el privilegio de la vestimenta para esto las leyes suntuarias son las que imponen y designan como una suerte de destino quienes pueden o no vestir determinadas telas y colores, por ejemplo. Tras sus sombras, pero saliendo a la luz de a poco se encuentra la burguesía, la verdadera auspiciante de la Moda con sus formas de producción características de la maquinaria industrial y sus formas de comercialización y difusión, nos encontramos con la moda burguesa, organizada ya en un sistema bien definido, no solo espacialmente con sus centros sino también con un ritmo acorde a las temporadas y las estaciones. Las leyes suntuarias que otrora restringían usos y costumbres quedan obsoletas para dejar paso a la ley del dinero cuyos principales propietarios son los burgueses que reunían en su figura el poder económico y político tras la Revolución Francesa en 1789. La Ilustración y el encomio a la razón universal son la fuente de legitimación del saber y la cultura, las medidas de las faldas, lo que se debe ocultar y dejar a la vista también se miden en los términos de la Razón. A continuación, y a mediados del siglo XX la etapa consumista de la moda entroniza a la juventud y la cultura de masas, en esta etapa el mercado es quien estipula y dicta la moda, permeando e incorporando a las masas en general a este gran sistema que es la Moda.

Es con la globalización cuando este sistema entra en un cismo como todo el paradigma de la Modernidad y se enfrenta a su reconversión, en una suerte de multidiversidad que puede leerse acorde a los postulados de la posmodernidad. A mediados del siglo XX, como sosteníamos más arriba, la moda se masifico de la mano de la cultura de masas y el consumo de grupos etarios como los jóvenes que son en definitiva quienes mejor la encarnan; con la crisis de la sociedad disciplinaria y sus instituciones, la moda como institución, como producto del imaginario social también muta. Adquiere las características del modelo general: global, sutil, líquida, arabesca, Hipermoda. Industria cultural con la capacidad de incluir en sus propuestas desde las orejas de Mickey hasta un cuadro y sus marcos, la Hipermoda es uno de los artilugios del capitalismo que mejor expresa la existencia contemporánea, el pensamiento en arabesco. La fragmentación del relato también aparece en las expresiones estéticas de la moda, como en los diversos desfiles de temporadas, por ejemplo y en los Fashion films que son nuevas expresiones para publicitar las marcas a par- 
tir de una historia breve en donde la principal protagonista son las prendas, prendas sin cuerpo ni órganos, como los maniquíes, muñecos sin alma. Si el cine tuvo en la moda una aliada implacable para difundir las fantasías de los espectadores; la Hipermoda se apropia de esta forma del movimiento y el tiempo del cine para hacerse protagonista.

\section{Estudio de caso: Cuba, Chanel, modelo de Hipermoda}

Primero el Papa Francisco, segundo el presidente Barack Obama, después un recital gratuito de los Rolling Stones, también el arribo a la isla de un crucero que había partido de Miami y, por último, como una confirmación más de la apertura al mundo, el desfile de la colección Crucero 2016-2017 de Chanel, la marca centenaria cuyo director creativo era Karl Lagarfeld. Si en 1989 el derrumbe del Muro de Berlín hizo que todo lo sólido se desvanezca en el aire, parafraseando primero a Karl Marx y luego a Marshall Berman (1998), la desterritorialización y reterritorialización del corazón, del espíritu y del cuerpo cubano por parte de los campos político-económicos, eclesiásticos y culturales coronan el triunfo del capitalismo en su etapa de hiperglobalización. Viva Coco, Cuba libre versaron las T-shirts diseñadas en colores pasteles, caribeños, texturas, volados, modelos cubanas, una pequeña orquesta y al final una batucada cubana, el capitalismo globalizado permite un gran espectro de hibridación cultural, se fueron dando cita en el Paseo del Prado. Reservado para pocos invitados, el pueblo cubano asistió desde los balcones de sus hogares o desde lejos. Con este testimonio la Hipermoda logra aún más diversidad y reinventa sus límites. La industria de la moda es un fenómeno que piensa con hipervínculos. Configura otros centros de difusión, interviene espacios públicos privatizándolos fugaz pero certeramente en un desfile, mixtura personajes. La controversial Coco Chanel y los también controversiales líderes de la Revolución cubana se componen en un cuadro donde las gorras y estampados militares se hicieron presentes para representarlos como propuesta de lujo y glamour que restituye la huella revolucionaria como forma sin contenido. La estetización de la existencia llevada a su máxima expresión kitsch. Este es el pensamiento posracionalista que se permite construir cosmogonías exóticas y posverdades.

Bajo el signo de la mercancía, todos los trabajos se intercambian y pierden su singularidad; bajo el signo de la moda, son el ocio y el trabajo los que intercambian sus signos. Bajo el signo de la mercancía, la cultura se compra y se vende; bajo el signo de la moda, son todas las culturas las que actúan como simulacros en una promiscuidad total (Baudrillard, 1976, p. 92).

Los coloridos, viejos e impecables autos acercaron a los modelos e invitados al Paseo del Prado. Recorriendo las calles de la ciudad en otro desfile en el que a su paso fueron esparciendo el deseo de consumo; como una performance sobre lo que siempre han hecho los turistas que llegan a la isla cumpliendo sus deseos. Cuba revolucionaria cede su paso a la isla como lugar de una promiscuidad total, donde la atractivo de la ropa y de la vida proviene de la libertad. 


\section{Rizomando}

La moda en su etapa global y digital deviene Moda Rizoma, dibuja con su esquema otra cartografía de sus actividades productivas, comerciales y de difusión. En consonancia con el paradigma digital colabora en la construcción de nuevas subjetividades e identidades, más individuales, efímeras; más libres y sutiles. Menos autoritaria, más inquieta e incierta, en proceso de aceleración constante pero no tanto como para generar su detenimiento definitivo. Propicia la libertad individual y reúne en lugar de la masa a la multitud atomizada que configura otros modelos culturales y reconfigura otras formas para el lazo social como se ha tratado de poner en evidencia en los breves ejemplos citados. Cuestiona unas prácticas y pone en evidencia otras, sin dejar de crear la fascinación que suscita el vestir y el cuerpo como comunicadores esenciales de la subjetividad a lo largo de la historia y de la subjetividad posmoderna que hemos tratado de analizar. Como ejemplo de esta subjetividad posmoderna y análisis final para retener y preguntar, cita Steele (2018) en su último libro Fashion Theory:

La moda se burla de la muerte -observó el filósofo Walter Benjamin-porque el tiempo de la moda es el tiempo del ahora (Jetztzeit). Y, sin embargo, la muerte habita en el corazón de la moda, porque, a diferencia del cuerpo que vive y muere, la moda no está ni viva ni muerta. De acuerdo con Benjamin, la esencia de la moda deriva de lo inorgánico (vestimenta, joyas). Hasta el rostro está cubierto de cosméticos. Como resultado la persona viva deviene en una suerte de maniquí (2018, p. 296).

La moda se burla de su hermana mayor, la muerte, y continua efectivamente su paso haciéndose camino como el rizoma.

La moda nos interpela al punto tal que, como se ha dado en estos últimos tiempos y gracias a la tecnología digital, es posible encontrarnos frente a frente con nuestro propio yo envejecido; para hacernos caer en una suerte de metáfora del zombie, nos devuelve nuestra propia imagen burlándose del tiempo y de la muerte para convertirnos en nuestros propios devenires y nuestros propios cadáveres, maniquíes, nosotros mismos convertidos en materia inorgánica y retenido para la posteridad, aun cuando no lleguemos a conocernos en tal estado.

Visualizamos nuestro yo, y así como lo hacen las joyas o las vestimentas y las aplicaciones destinadas a ello, la misma aplicación nos permite, a modo de una imagen fetiche, volvernos viejos, adelantar el tiempo vertiginosamente, nos convierte en un cadáver digital, puro ente virtual e inorgánico. Logra a través de otra de sus manifestaciones digitales modificar nuestras percepciones que a modo jocoso nos extrae una sonrisa que es más que eso, porque la Hipermoda también habla de un futuro que aún no podemos vislumbrar, ni cuestionar o gestionar porque nos encontramos demasiado obnubilados ante una realidad que cambia incesantemente.

La moda pone de moda, como lo común que se reúne en un punto, las aplicaciones para que de forma virtual probemos las mejores marcas de cosméticos, a través de los filtros de las aplicaciones. Lancöme y Dior nos pintan las caras como mascaras en otro intento 
más de convertirnos en protagonistas de sus campañas publicitarias. Lo lúdico como otra manifestación de la moda desde hacerse maquillar o convertirse en anciano o anciana muestra a la subjetividad avasallada por lo digital, embriagada como para poder responder certeramente a tal devenir.

\section{Conclusión}

A modo de conclusión se puede argüir que la moda rizoma o Hipermoda construye apariencias (Saulquin, 2014) como siempre, desde sus orígenes ha realizado la moda; sin embargo en esta etapa la exaltación del individualismo y las tecnologías digitales nos hace coincidir con Saulquin (2014) en que:

Las facilidades que acercan las nuevas tecnologías permiten desplazar el concepto de ser y estar en un mundo en soledad, porque los seres humanos contienen multitudes en su interior conectadas digitalmente. De esta manera y Como consecuencia de esta invasión y hasta saturación de los medios audiovisuales, se está desarticulando la imagen que cada uno tiene de sí mismo, porque en lugar de ser la resultante de un diálogo entre ser interior y el contexto, está siendo moldeada completamente por el afuera (p. 190).

El afuera entendido como los medios audiovisuales y digitales, la vida privada expuesta en su máxima expresión, y la espera constante de la mayor cantidad de likes, amigos y seguidores que las redes sociales puedan brindar. De esta manera en la moda rizoma es la apariencia la que es exacerbada a través de esos muñecos sin alma, maniquíes portadores de una razón posorgánica que se manifiesta como una nueva subjetividad, la subjetividad posmoderna, digital, rizomática.

\section{Lista de Referencias Bibliográficas}

Baudrillard, J. (1976). La Economía Política del Signo. Madrid, España: Siglo XXI.

Berman, M. (1998). Todo lo sólido se desvanece en el aire. México: Siglo XXI.

Byung-Chul, H. (2013). La Sociedad de la Transparencia. Madrid: Herder.

Carlyle, T. (1976). Sartor Resartus. Madrid, España: Espiral Fundamentos.

Castoriadis, C. (2013). La Institución Imaginaria de la Sociedad..Buenos Aires, Argentina: Tusquets Editores.

Deleuze, G. (1991). Posdata sobre las sociedades de control. Montevideo, Uruguay: Nordam. Deleuze, G y Guattari, F. (2004). Mil Mesetas. Valencia, España: PreTextos.

Entwistle, J. (2002). El Cuerpo y la Moda. Buenos Aires, Argentina: Paidós.

Fischer, H. (2011). Planeta Hiper, del pensamiento lineal al pensamiento en arabesco. Buenos Aires, Argentina: Eduntref. 
Foucault, M. (1995). Vigilar y Castigar. México: Siglo XXI.

Rivière, M. (1994). Moda: ¿Comunicación o Incomunicación?. Barcelona, Madrid: Paidós.

Saulquin, S. (2014). Politica de las Apariencias. Buenos Aires, Argentina: Paidós.

Sibilia, P. (2010). El Hombre Postorgánico. Buenos Aires, Argentina: Fondo de Cultura Económica.

Steele, V. (2018). Fashion Theory, Hacia una teoría cultural de la moda. Buenos Aires, Argentina: Ampersand.

Vattimo, G. (1989). La sociedad transparente. Barcelona, España: Paidós.

\title{
Otras fuentes consultadas
}

Saulquin, S. (2010). La Muerte de la Moda, el día después. Buenos Aires, Argentina: Paidós. Leopardi, G. (1964). Diálogos. Buenos Aires, Argentina: Espasa Calpe.

Martínez Barreiro, A. (1998). La Moda en las Sociedades Modernas. España: Tecnos.

\begin{abstract}
This writing tries to show how fashion is alike to its own logic, it is renewed, and it resurfaces from the ashes like the Phoenix Bird; far from perishing, it is resignified. Modifying the fields of production and consumption, altering the manifest senses in the social imaginary, in the subjects; adapting to the new rhizomatic paradigm in which individualism and globalization, interconnected humanity, technological prosthetics are the cause and consequence of these new worldviews. Fashion is not exempt from this and manifests, also, in rhizome.
\end{abstract}

Keywords: Fashion - hyperfashion - society - rhizome - new subjectivities - culture - paradigms.

Resumo: Esta escrita tenta dar conta de como a moda é semelhante à sua própria lógica, é renovada e ressurge das cinzas como a fênix; longe de perecer, é ressignificado. Modificando os campos de produção e consumo, alterando os sentidos manifestos no imaginário social, nos sujeitos; adaptando-se ao novo paradigma rizomático em que o individualismo e a globalização, a humanidade interconectada, a prótese tecnológica são a causa e a conseqüência dessas novas visões de mundo. A moda não está isenta disso e se manifesta também no rizoma.

Palavras chaves: Moda - hipermodal - sociedade - rizoma - novas subjetividades - cultura - paradigmas.

[Las traducciones de los abstracts fueron supervisadas por el autor de cada artículo] 